\title{
The Effect of Degradation Time Variation on Porous Magnesium Implant Bone Scaffold
}

\author{
Hasan Basri ${ }^{1, *}$, Ardiansyah Syahrom ${ }^{2,3}$, Amir Putra Md $\mathrm{Saad}^{2,3}$, Rabiatul Adibah $\mathrm{AR}^{2,3}$, \\ Tri Satya Ramadhoni ${ }^{1}$, Risky Utama Putra ${ }^{1}$, Apreka Diansyah ${ }^{1}$ \\ ${ }^{1}$ Department of Mechanical Engineering, Faculty of Engineering, Universitas Sriwijaya, 30622 \\ Inderalaya, Kabupaten Ogan Ilir, Indonesia \\ ${ }^{2}$ Department of Applied Mechanics and Design, Faculty of Mechanical Engineering, Universiti \\ Teknologi Malaysia, 81310 Sekudai, Johor, Malaysia \\ ${ }^{3}$ Sports Innovation and Technology Centre (SITC), Institute of Human-Centred and Engineering \\ (IHCE), Universiti Teknologi Malaysia, 81310 Sekudai, Johor, Malaysia
}

\begin{abstract}
This paper proposes a modeling approach for biodegradation of implant-bone scaffolds. A Computer simulation was performed to determine the wall shear stress (WSS) and permeability of simulated body fluid (SBF) with a constant flow rate of $0.025 \mathrm{ml} / \mathrm{min}$. In this study, four morphological samples were used to immersion time from 0 to 72 hours. Each specimen was given a different bone strain (1000-3500 $\mu$ strain) which created a variation of displacement in the bone scaffold. The method used in the simulation was the fluid-structure interaction (FSI). The pressure drop through the specimen decreases linearly, the permeability increases as the porosity increases, and the mean wall shear stress decreases due to the length of the immersion time. It was obtained that the permeability values of the implant-bone scaffold increases from $7.79 \times 10^{-10}$ $\mathrm{m}^{2}$ to $1.09 \times 10^{-9} \mathrm{~m}^{2}$ and the mean shear stress values decrease from $2.86 \times 10^{-3} \mathrm{~Pa}$ to $1.38 \times 10^{-3} \mathrm{~Pa}$.
\end{abstract}

\section{Introduction}

Tissue engineering today generally uses porous scaffolds to allow nutrients to pass through bone scaffolds for tissue regeneration. The physiological action is very important for bone homeostasis which produces various loads on human bones during activity. The average load when walking is $3.1 \mathrm{x}$ body weight (BW), jogging is $6.2 \mathrm{x} \mathrm{BW}$, running fast is $8.7 \mathrm{x}$ BW. Body weight is based on $75 \mathrm{~kg}[1,2]$ when variations in bone strains differ $(1000-3500 \mu \varepsilon)$ the pressure generated in the bone becomes different.

The behavior of biodegradation from biodegradable magnesium bone scaffolds must be thoroughly investigated when applied to the body because the magnesium bone scaffold can be degraded together with the formation of new bone so that there is no need for surgery a second time. The bone scaffolds influence the transport system of oxygen and

*Corresponding author: hasan_basri@unsri.ac.id 
biological fluids for their maintenance and survival evaluating the mechanism of fluid flow and then, permeability [2] or the shear stress on the wall is an important parameter because of its direct effect on the cells in bone scaffolds. This scaffold must allow the distribution of nutrients, gas diffusion, and waste emissions through channels [3]. Permeability in bone scaffold implants is an important factor in predicting cell distribution. Actually, porosity may have an effect on cell composition, including those caused by biophysical stimulants, allowing those that will form the desired new tissue in porous artificial bone scaffolds [4]. Researchers have conducted an investigation to find factors that can control permeability and shear stress effectively. In the biological stimulants, the shear stress by the liquid stream has the most noticeable impact. O'Brien et al. [5] carried out research on mathematical analysis and scientific experimental to discover permeability that relies upon porosity. The different study explores impacts of porosity on permeability through computational and experimental investigation.

Aside from the mechanobiological developments that influence the nature of the bone framework with the biological conditions, various necessities must be met through the plan of microscopy and macro sizes of permeable structures in bone scaffold [8]. When designing the morphology of bone scaffolds, biomechanical modulation involves mutual calculation of bio-fluid and structural characteristic to be an important aspect of this study [9]. The minimum pore size used is $80 \mu \mathrm{m}$ determined for optimal cell penetration of hydroxyapatite scaffolding [10]. Other studies also report pore sizes of more than $300 \mu \mathrm{m}$ which can increase cell proliferation [11]. However, [12] had a higher bone formation in artificial bone scaffolds at pore sizes of $325 \mu \mathrm{m}$. In addition, large capillary densities were given for porosity higher than $140 \mu \mathrm{m}$ [13] and in the range of 300-1200 $\mu \mathrm{m}$ there were no significant differences in the process of bone formation [14]. In the case of porosity, values above $85 \%$ are seen to increase the effect of cell penetration up to $400 \mu \mathrm{m}$ while porosity above $75 \%$ is recommended to ensure cell proliferation [15]. Another study conducted by Danilevicius et al. [16]. To discuss this problem, more knowledge is needed about natural ways to analyze the behavior of porous magnesium biodegradation during immersion testing in the chamber. These experimental works and computer simulation to determine the influence of porous bone scaffolding architecture of human physical activity and biodegradation were studied by $[17,18,24]$. The current study only conducts a simulation study using the FSI method to investigate the effect of degradation time variation on porous magnesium implant bone scaffold with constant SBF flow rate of $0.025 \mathrm{ml} / \mathrm{min}$.

\section{Materials and Methods}

\subsection{Overview of Previous Research}

The volume of scaffold used is a cube in size $(5 \times 5 \times 3 \mathrm{~mm})$, the material used is a pure magnesium (stem diameter $24.4 \mathrm{~mm}$ and purity of $99.9 \%$ produced by Good Fellow Inc., Cambridge, UK) has interlocking holes relating that is made using CNC machines. Bone scaffold samples were given pores made using a drill with a diameter of $800 \mu \mathrm{m}$. Then a porous magnesium bone scaffold implant was obtained with a porosity level of $30 \%$ at a volume of $52.87 \mathrm{~mm}^{3}$, which can be shown in Figure 1c $[17,18]$. The morphology of a specimen is shown in Table 1. 
Table 1. The morphological details of porous magnesium scaffold specimens [17,18].

\begin{tabular}{|c|c|c|c|}
\hline Porosity (\%) & Volume $\left(\mathbf{m m}^{\mathbf{3}}\right)$ & Surface area $\left(\mathbf{m m}^{\mathbf{2}} \mathbf{)}\right.$ & Surface area per volume $\mathbf{( m}^{-\mathbf{1}} \mathbf{)}$ \\
\hline 30 & 52.87 & 189.30 & 3580.48 \\
\hline
\end{tabular}

Specimens with morphological samples of $30 \%$ porosity selected based on morphology on the cancellous bone after experimental immersion test, four porous magnesium samples prepared in the scope of this study will be tested with four variations of immersion time. The constant flow rate of $0.025 \mathrm{ml} / \mathrm{min}$ from bone marrow cancellous bone structure was translated into experimental settings in vitro, as shown in Figure 1a and Figure 1b [17,18] using a laminar fluid flow type in the test channel with a set length (L) of $41 \mathrm{~mm}$. Porous magnesium is tested for immersion tests for periods of 0 to 72 hours.

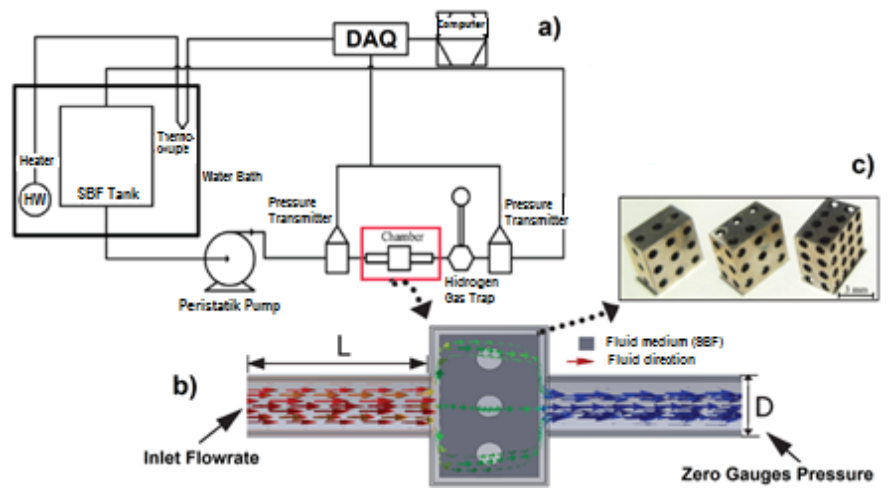

Fig. 1. The dynamic immersion testing rig system: a) a schematic of the test rig, b) a detailed illustration of the SBF fluid direction in the chamber, and c) a photograph of the morphology of bone scaffolds $30 \%$ porosity $[17,18]$.

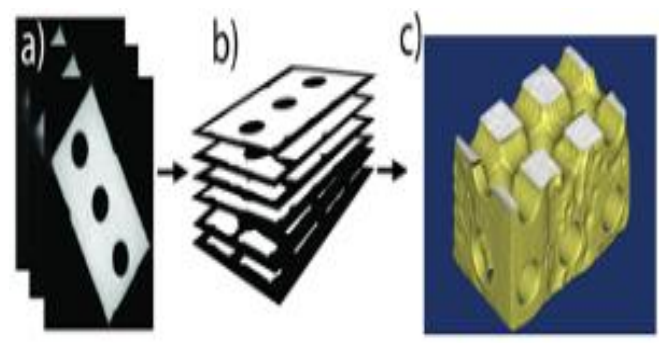

Fig. 2. Description of the bone scaffolding preparation process: a) raw $\mu \mathrm{CT}$ data, b) image stacks segmentation and c) 3D model reconstruction after degradation $[17,18,24]$.

\subsection{Three-Dimensional Models}

To find the behavior of magnesium porous scaffold fluid flow characteristic, computerassisted designs were originally made using CAD software as shown in Figure 2. One sample of $30 \%$ porosity with each immersion group of 24, 48 and 72 hours was scanned using a $\mu \mathrm{CT}$ scanner (Skycan 1172, Kontich, Belgium). In general, $\mu \mathrm{CT}$ is used to measure various geometry scaffold parameters after degradation for time 24, 48 and 72 hours of immersion. 
The illustrated step-by-step process $[17,18,24]$ to obtain the three models of the bone scaffold from raw $\mu \mathrm{CT}$ images was shown in Figure 2. Representative cross-sectional images and morphology of specimens after degradation are presented respectively in Figure $2 \mathrm{a}$ and Figure $2 \mathrm{~b}$. Data generated from the $\mu \mathrm{CT}$ process as shown in Figure $2 \mathrm{c}$ is ready to be transferred to MIMICS software (Materialize, Belgium). Finally, the bone scaffold model after degradation is obtained by commands from the 3D mask counter software as shown in Figure 2c. Reconstructed 3 samples of porous magnesium specimens after degradation as shown in Figure 3 is exported as a stereolithography (STL) format which shows the surface network $[17,18,24]$.

\subsection{Simulation Procedure Fluid-Structure Interaction (FSI)}

Models for fluid flow and solid model are solved by software COMSOL Multiphysics. The properties of SBF are set with a density value of $1000 \mathrm{~kg} / \mathrm{m}^{3}$ and a viscosity value of 0.001 Pa.s as shown in Figure 4.

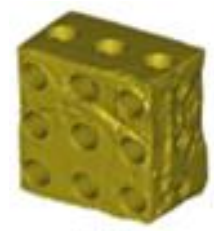

24

Hours

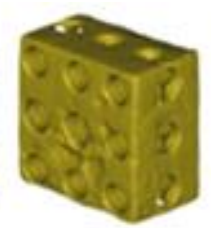

48

Hours

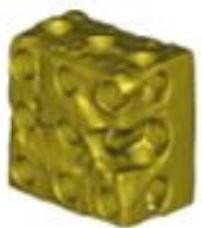

72

Hours

Fig. 3. 3D reconstruction results of bone scaffolds by comparison of biodegradation time variations $[17,18,24]$.

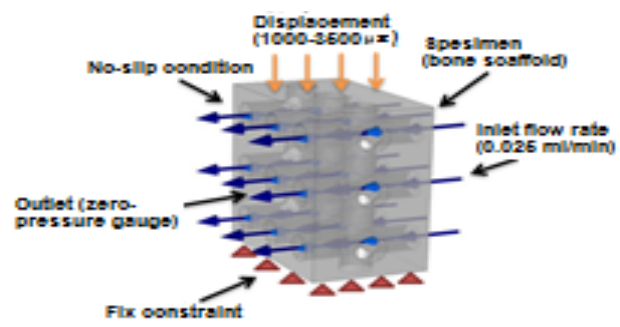

Fig. 4. The boundary conditions used in FSI simulation.

Finally, the data of the average pressure reduction obtained from the Comsol Multiphysics software to simulate each bone scaffold sample model and calculate the permeability coefficient using Darcy's law with the following equation.

$$
\mathrm{Q}=\left(\frac{\mathrm{kA}}{\mu}\right)\left(\frac{\Delta \mathrm{P}}{\mathrm{L}}\right)
$$

Where, $\mathrm{Q}$ is the flow rate $\left(\mathrm{m}^{3} / \mathrm{s}\right), \mathrm{A}$ is the surface area $\left(\mathrm{m}^{2}\right), \mu$ is the dynamic fluid viscosity (Pa.s), $\Delta \mathrm{P}$ is the pressure drop $(\mathrm{Pa}), \mathrm{L}$ is the length of the specimen $(\mathrm{m})$ and $\mathrm{k}$ is the permeability $\left(\mathrm{m}^{2}\right)$. For each simulation, pressure data i.e inlet pressure and the outlet pressure are drawn on the modeling of the fluid passing through the bone scaffold, precisely $1.5 \mathrm{~cm}$ at the inlet and outlet points from the center point of the bone scaffold.

\subsection{Meshing Sensitivity Study}


A convergence study was conducted in which around 300,000 elements were needed to determine the mesh results that could be relied upon to simulate a bone scaffold sample (see Figure 5) and visualize the distribution of elements with a scaffold mesh with tetrahedral meshing model (see Figure 6). The Von Misses stress value of the analysis must be independent of mesh density, where the von wall loses voltage and the velocity is directly interconnected, therefore the FSI method is a multi-physical multiplication between laws describing fluid dynamics and structural mechanics. All simulation processes are carried out using Dell Type Precision Workstation T54000 with Intel Xeon microprocessor using a RAM capacity of 128 GB.

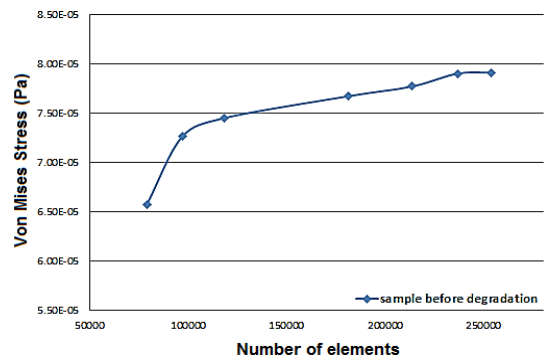

Fig. 5. The study of the convergence of mesh analysis between Von Mises stress values and number of elements

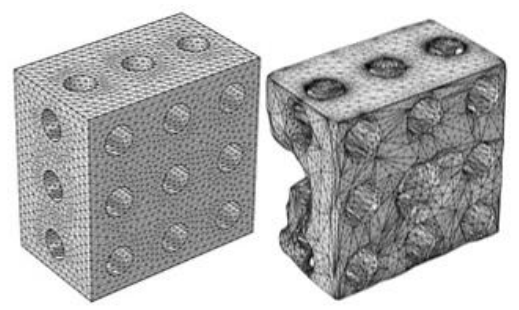

Fig. 6. A sample of morphology 3D reconstructed process meshing of bone scaffold before and after biodegradation.

\section{Results and Discussions}

The SBF flows inside the chamber which will pass through the bone scaffold to produce a fluid shear stress on the surface of the bone scaffold. The result of $3 \mathrm{D}$ bone scaffold simulation using the FSI method is shear stress and pressure. Data from the simulation results are processed to find permeability, volume, surface area and porosity in the bone scaffold.

To determine the performance and reliability of the scaffold model in the analysis using the FSI method, the pressure drop $(\Delta \mathrm{P})$ with a constant SBF flow rate of $0.025 \mathrm{ml} / \mathrm{min}$. From the simulation results using the FSI method with a variation of the scaffolding immersion time as shown in Figure 7, it was found that the pressure drop $(\Delta \mathrm{P})$ through the specimen decreased linearly because of the porosity increased due to the length of immersion time. The results sounded good with previously reported experimental work on perfusion experiments on rabbit bone graft [19].

Figure 8 shows a comparison between the results of cancellous bone permeability results from experimental studies and previous simulations with scaffold bone permeability. Cancellous bone samples are taken from the vertebral body of the calcaneus, femoral bone 
[19] and lumbar vertebrae [20]. Based on our literature search, computational work has been reported on bone value and cancellous permeability with a value of $1.4 \times 10^{-7} \mathrm{~m}^{2}$ to $2.8 \times 10^{-7} \mathrm{~m}^{2}$. This study shows that the obtained permeability values start from $7.79 \times 10^{-10}$ $\mathrm{m}^{2}$ to $1.09 \times 10^{-9} \mathrm{~m}^{2}$. The results showed good agreement with cancellous bone in computational simulations in previous studies.

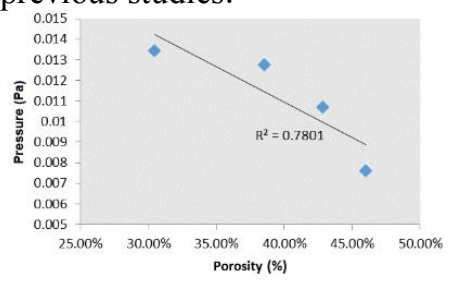

Fig. 7. The relationship between the decrease $(\Delta \mathrm{P})$ and the porosity variations caused by the length of time degradation.

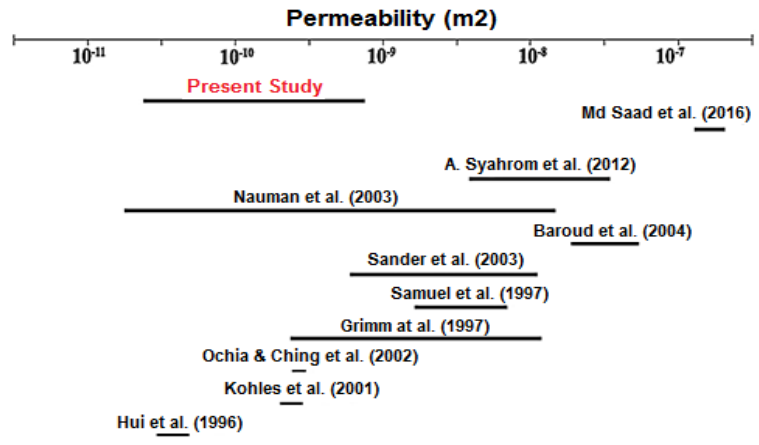

Fig. 8. Comparison between results of cancellous bone permeability from previous experimental and simulation studies and bone scaffold permeability in this study.

The correlation between permeability and porosity of bone scaffolds after the immersion test is illustrated in Figure 9. Permeability values in all samples increased with increasing porosity due to immersion time. Sample 0 hour shows the sample before degradation and a period of 24 to 72 hours shows the sample after degradation. The important correlation point between the permeability and porosity is 0.5634 . Although those discussing permeability of porous structures is quite numerous and in demand, some of them have not studied for the scaffold samples before and after degradation using computational methods with the FSI method. The results of this study show a permeability graph similar to that found in previous experimental and simulation studies [21].

The study of permeability of bone scaffolding is very important to know its mechanical properties because it states the ideal structural ability to carry nutrients through the bone scaffold. The higher the permeability value of the bone scaffold, the nutrients will be carried well because of the high porosity value. The right speed between permeability and mechanical strength is very important to achieve optimal performance of the ideal structure [22]. In the case of bone scaffolding, there is a contradiction between optimizing the size of porosity and mechanical properties. For example, the findings by [23], low permeability and initial porosity resulted in a faster rate of L-prolyl-L-Leucylglycinamide (PLG) scaffolding. Therefore, considering these case factors, bone regeneration factors include mechanical requirements that correspond to the desired characteristics and diffusion of life. One way that can be done to achieve this goal is to emit porosity in digging with nutrients and matching it with biomaterials that can provide mechanical properties that are in accordance with the human body. 
The mean fluid shear stress values are then determined for each specimen sample with immersion time variation as shown in Figure 10. Average WSS for samples 24, 48, and 72 hours, respectively, are $2.86 \times 10^{-3} \mathrm{~Pa}, 1.40 \times 10^{-3} \mathrm{~Pa}$, and $1.38 \times 10^{-3} \mathrm{~Pa}$. From previous work that conducted by Md Saad [17,18] and H. Basri et al. [24], the shear stress obtained was $0.12 \times 10^{-5} \mathrm{~Pa}-5.74 \times 10^{-5} \mathrm{~Pa}$. In this study, the value of shear stress obtained is higher than the value of the shear stress of the previous study, this can occur due to different boundary conditions and method of analysis. Md Saad [17,18] and H. Basri et al. [24] conducted the simulation in their study using CFD method and the boundary condition of the bone scaffold was not integrated with bone strain.

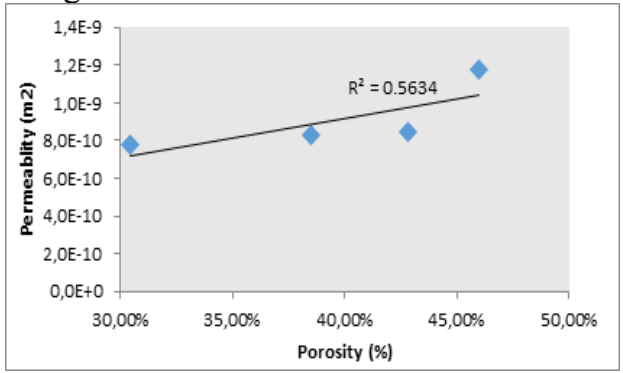

Fig. 9. The relationship between permeability and bone scaffold porosity.

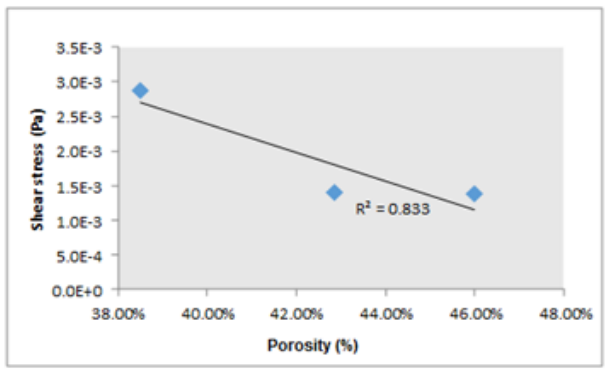

Fig. 10. The plot of shear stress and porosity of bone scaffolds after degradation.

Shear stress contour plot of the sample after degradation with a flow rate of 0.025 $\mathrm{ml} / \mathrm{min}$ is shown in Figure 11. Contour plots show shear levels acting on open surfaces which are localized into porous specimens. To determine which wall units are localized in a porous structure for all samples after being degraded by time, the shear stress level in the area is indicated by the zoom mark selected.

Bone marrow is a liquid that carries nutrients and oxygen as it passes through the cancellous bone. SBF is representative of the movement of bone marrow shear currents in bone scaffold structures and also decreases bone scaffolding. 


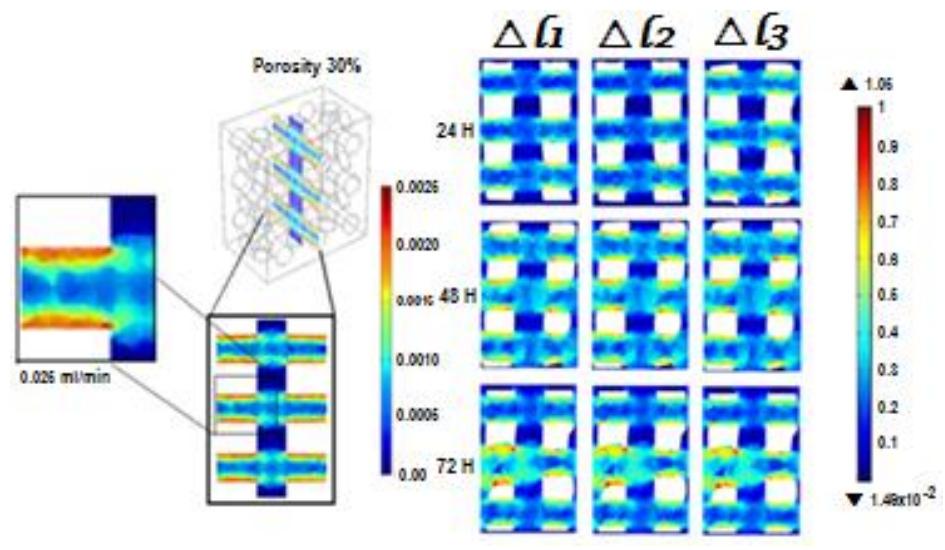

Fig. 11. The contour plot of shear stress on the porous bones scaffold.

\section{Conclusions}

Permeability is one of the properties of bone scaffolding, which is influenced by surface area, porosity, flow rate, and viscosity. The response to shear stress fluids and the effect of permeability on biodegradation because the porous magnesium immersion time is very influential to predict effectively in vivo testing, we can develop appropriate medical implants against drug and nutrient delivery systems through implant bone that can regenerate while new bone grows and replace damage in the bone area dead with bone scaffold implants.

From the results and discussions above, it can be concluded as follows:

1. The pressure drop $(\Delta \mathrm{P})$ through the specimen decreases linearly, the permeability value increases as the porosity increases, and the mean wall shear stress decreases due to the length of immersion time $0,24,48$ and 72 hours.

2. The permeability values of the implant-bone scaffold increases from $7.79 \times 10^{-10} \mathrm{~m}^{2}$ to $1.09 \times 10^{-9} \mathrm{~m}^{2}$

3. The mean wall shear stress values decrease from $2.86 \times 10^{-3} \mathrm{~Pa}$ to $1.38 \times 10^{-3} \mathrm{~Pa}$.

\section{Acknowledgments}

This study was part of an International Research Collaboration between Universitas Sriwijaya, Indonesia and the Universiti Teknologi Malaysia, Malaysia.

\section{References}

1. C. M. Perrault, "In vitro bone cell models:impact of fluid shear stress on bone formation", vol. 4(2016).

2. A. G. Mitsak, J. M. Kemppainen, M. T. Harris, S. J. Hollister. J. Tissue Eng.- Part A, 17, 13-14 (2011).

3. V. Serpooshan et al. J. Acta Biomater 6, 10 (2010).

4. W. J. Hendrikson, A. J. Deegan, Y. Yang, C. A. Van Blitterswijk, E. Farrell, 5 (2017).

5. F. J. O. Brien, B. A. Harley, M. A. Waller, I. V Yannas. J. Technol. Heal. Care 15 (2007). 
6. A. Lesman, Y. Blinder, S. Levenberg. Biotechnol. Bioeng 105, 3 (2010).

7. F. Zhao, T. J. Vaughan, L. M. McNamara. J. Mechanobiol 15, 3 (2016).

8. C. T. Koh, D. G. T. Strange, K. Tonsomboon, M. L. Oyen. J. Acta Biomater 9 (2013).

9. Q. Zhang, H. Lu, N. Kawazoe, G. Chen. J. Acta Biomater10, 5 (2014).

10. F. R. Rose, L. A. Cyster, D. M. Grant, C. A. Scotchford F. R. Rose, L. A. Cyster, D. M. Grant, C. A. Scotchford, S. M. Howdle, K. M. Shakeshef. J. Biomaterials 25, 24 (2004).

11. S. Lien, L. Ko, T. Huang. J. Acta Biomater 5, 2 (2009).

12. C. M. Murphy, M. G. Haugh, F. J. O. Brien. J. Biomaterials 31, 3 (2010).

13. F. M. Klenke, Y. Liu, H. Yuan, E. B. Hunziker, K. A. Siebenrock, W. Hofstetter. J. Biomed. Mater. Res.-Part A 85, 3 (2008).

14. S. J. Hollister. J. Craniofac. Res 8, 3 (2005).

15. J. Zeltinger, D. Ph, J. K. Sherwood, D. Graham, R. Müeller, L. G. Griffith 7, 5 (2001).

16. P. Danilevicius, L. Georgiadi, C. J. Pateman, F. Claeyssens, M. Chatzinikolaidou, M. Farsari. J. Appl. Surf. Sci 336 (2015).

17. A. P. Md. Saad et al. J. Corros. Sci (2016).

18. A. P. Md. Saad et al. J. Mater. Des 122 (2017).

19. P. W. Hui, P. C. Leung, A. Sher, J. Biomech 29, 1 (1996).

20. G. Baroud, R. Falk, M. Crookshank, S. Sponagel, T. Steffen. J. Biomech 37, 2 (2004).

21. C. G. Jeong, S. J. Hollister. J. Biomed. Mater. Res.-Part B Appl. Biomater 93, 1 (2010).

22. A. Syahrom, M. Rafiq, A. Kadir, J. Abdullah, A. Öchsner. J. Med. Eng. Phys 35, 6 (2013).

23. C. Agrawal, J. McKinney, D. Lanctot, K. Athanasiou. J. Biomaterials 21, 23 (2000).

24. H. Basriet al., Malaysian Journal of Fundamentals and Applied Sciences (2017). 